\title{
Calculation of volumetric sound field of pulsed air-coupled ultrasound transducers based on single plane measurements
}

\author{
Sergio J. Sanabria, Member, IEEE, Torben Marhenke, Roman Furrer and Jürg Neuenschwander
}

\begin{abstract}
Quantitative and reproducible air-coupled ultrasound (ACU) testing requires characterization of the volumetric pressure fields radiated by ACU probes. In this work, a closed form re-radiation method combining the Rayleigh-Sommerfeld integral and time reversal acoustics is proposed, which allows calculation of both near field and far field based on a single plane measurement. The method was validated for both three-dimensional (circular, square) and two-dimensional (rectangular) planar transducers in the $50 \mathrm{k}-230 \mathrm{kHz}$ range. The pressure fields were scanned with a calibrated microphone. The measurement window was at least four times the size of the transducer area and the grid step size was one third of the wavelength. Best results were observed by acquiring the measurement plane at near field distance. The method accurately reproduces pulsed ultrasound waveforms and pressure distributions (rmse $<2.5 \%$ in far field and $<5.5 \%$ in near field), even at the transducer radiation surface. The effects of speed of sound drifts during the scan in the pressure were negligible $(<0.3 \%)$. The re-radiation method clearly outperforms conventional baffled piston models. Possible applications are transducer manufacture control (imperfections at radiation surface) and calibration (on-axis pressure, side lobes, beam width), together with generation of accurate source functions for quantitative NDE inverse problems.
\end{abstract}

Index Terms-Air-coupled ultrasound, time reversal acoustics, NDE transducer modeling, wave propagation.

\section{INTRODUCTION}

A ir-coupled ultrasound (ACU) has gained importance over the last decade for non-destructive evaluation (NDE) of material damage (cracks, delamination, impacts...), mechanical properties (stiffness, density, anisotropy...) and internal structure (porosity, heterogeneities...) [1-3]. A variety of applications have been developed in the frequency range from $20 \mathrm{kHz}$ to $5 \mathrm{MHz}$ for aerospace, civil engineering, food, textile,

Manuscript received Xxxxxxxx XX, 2017; accepted Xxxxxxxx XX, 201X. Date of publication Xxxxxxxx XX, 201X; date of current version Xxxxxxxx XX, 201X. This work was supported by the Swiss national Science Foundation under contract 200021-115920. (Corresponding author: Sergio J Sanabria).

S. J. Sanabria was with the Swiss Federal Laboratories for Materials Science and Technology, Empa, 8600 Dübendorf, Switzerland. He is pharmacy and medical industries. The main advantage is that no coupling medium is needed between ultrasonic transducer and test sample, which avoids sample contamination and allows for easy integration of ACU transducers into mechanized scanning systems of production lines. However, due to quasispecular reflections at the sample surfaces, only $<0.5 \%$ of the pressure field excited in air is transmitted through the test material. Focused transducer technologies are available, which achieve high lateral resolution for thin composites [4-6], which are typically $<10 \mathrm{~mm}$ thick. For thick materials $(>100 \mathrm{~mm})$ in civil engineering, such as concrete or wood, planar transducers are typically used [7] in order to optimize efficiency. Planar transducers are directive sources with large active areas, over which the ultrasound pressure field is spread, which are well above the wavelength size. This leads to image blurring and a lower lateral resolution than Rayleigh's limit. The interaction of ultrasound with material features is a complex process limited by diffraction, refraction and mode conversion effects, which if not accounted for, reduce both defect sensitivity and resolution. A variety of ultrasound signal processing methods, such as deconvolution [8], time reversal processing [9] or diffraction tomography [10], can improve the quality of ultrasound images, provided that the excited ultrasound fields are accurately characterized. Quality control of ACU systems also requires a careful calibration of the transducers to ensure the reproducibility of the measurements. It is therefore necessary to provide cost-effective methods to characterize the sound pressure distribution in air radiated by an ACU probe.

Direct measurement of the three-dimensional ACU pressure field is possible by mechanically scanning a calibrated point receiver over a measurement grid. The condenser microphone used in this work provides a flat response in a frequency range $2-140 \mathrm{kHz}$ [11], however, special microphones can reach to frequencies below $0.02 \mathrm{~Hz}$ and above $1 \mathrm{MHz}$ [12]. In addition, electrical scanning can be performed with ultrasonic arrays to shorten the measuring time $[13,14]$. The major disadvantage of direct measurements of the sound pressure is the long measuring time, since ultrasound waves propagate at finite speed of sound $c(343 \mathrm{~m} / \mathrm{s})$ from source to receiver at each

now with the Computer Vision Laboratory, ETH Zurich, 8092 Zurich, Switzerland (e-mail: ssanabria@ethz.ch).

T. Marhenke is with the Institute of Dynamics and Vibration Research, Leibniz Universität Hannover, D-30167 Hannover, Germany.

R. Furrer and J. Neuenschwander are with the Swiss Federal Laboratories for Materials Science and Technology, Empa. 


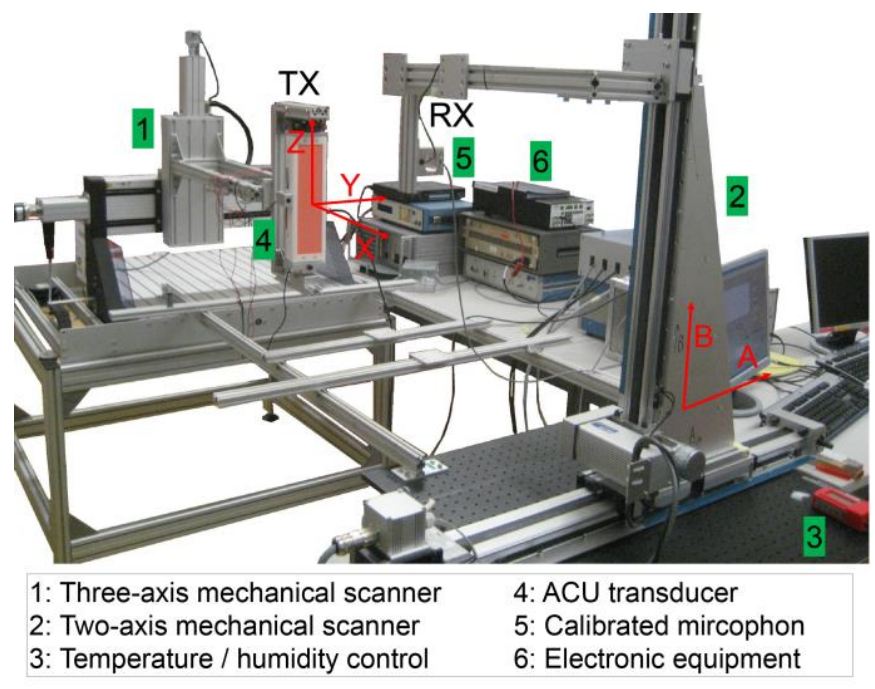

Fig. 1. Air-coupled ultrasound (ACU) measurement setup.

measurement point. For example, an efficient implementation of 30'000 measurement points in a volume of $1 \mathrm{~m}^{3}$ took about $8 \mathrm{~h} \mathrm{[11].} \mathrm{Another} \mathrm{difficulty} \mathrm{is} \mathrm{to} \mathrm{accurately} \mathrm{measure} \mathrm{the} \mathrm{near}$ field close to the transducer's radiation surface. This field shows an inhomogeneous interference pattern, which requires dense sampling, and is strongly affected by the presence of the point receiver, which creates reverberation artifacts. For these reasons, it is desirable to determine the sound field in only a small, easy to measure, region and to reconstruct the other parts of the pressure field based on a wave propagation model. Alternatively, full-field sound field measurements can be obtained with optical techniques such as refracto-vibrometry, TV holography, Schlieren and light diffraction tomography [15-20], whereby projections of the transmitted or scattered light are converted into sound pressure distributions. However, these methods require complicated (and costly) test rig setups.

Numerical methods are used to model and validate the influence of transducer material designs in excited ACU pressure fields, the interaction of ACU pressure fields with light sources, or the propagation of excited ACU beams in solid objects for NDE, among others. Popular methods are the finite element method (FEM) [17, 21-23] and finite-difference timedomain analysis (FDTD) $[24,25]$. While these methods are very flexible, they require a discretization of the full wave propagation domain and discretization steps $h$ of at least one order of magnitude smaller than the wavelength $\lambda$, with typically $h<\lambda / 20$. Due to the small wavelengths in air, this leads to computationally prohibitive requirements for free-space characterization of the fields radiated by an ACU source.

Closed-forms solutions have been proposed, which, given a source excitation, allow direct calculation of the unbounded space-time sound fields. In this case, the wave propagation is significantly simplified, since it only involves a single linear and uncompressible medium. A baffled piston model is typically used [14, 26, 27], which assumes a constant vibration distribution along the transducer surface. Based on the separate measurement of plane and edge wave components, this method provides reasonable results for the fields along the transducer axis [28]. However, this is only a coarse approximation of the field radiated by real ACU transducers, which show heterogeneous surface vibration. A more precise approach is to measure the vibration distribution over the transducer surface with a laser vibrometer and to simulate the radiated sound pressure distribution based on a Rayleigh-Sommerfeld integral $[29,30]$. However, accurate vibration measurements are only possible for flat transducer surfaces and the method is not adequate for textile or grid materials, which are often used as matching layers in ACU transducers [31] for NDE of thick composites [7, 32-35].

Several theoretical works have shown that a pressure measurement over a closed surface is sufficient for the characterization of the full three-dimensional acoustic field (acoustic holography) [20, 36-39]. These methods have been applied to the characterization of the fields radiated by waterimmersed ultrasound transducers [40-43] and contact ultrasound probes [19]. However, since ACU is a more recent technology, ACU transducers have received considerably less attention. [13] used single-plane measurements of the sound field radiated by an ACU transducer as input excitation to a phantom model. However, to the best of our knowledge holographic calculation of the time-space fields radiated by ACU transducers has still not been experimentally validated. Specific challenges are the small wavelength and the variation of the speed of sound with environmental conditions. Therefore, the discretization of the wave propagation equations needs to be efficiently addressed, and experimental uncertainties need to be characterized.

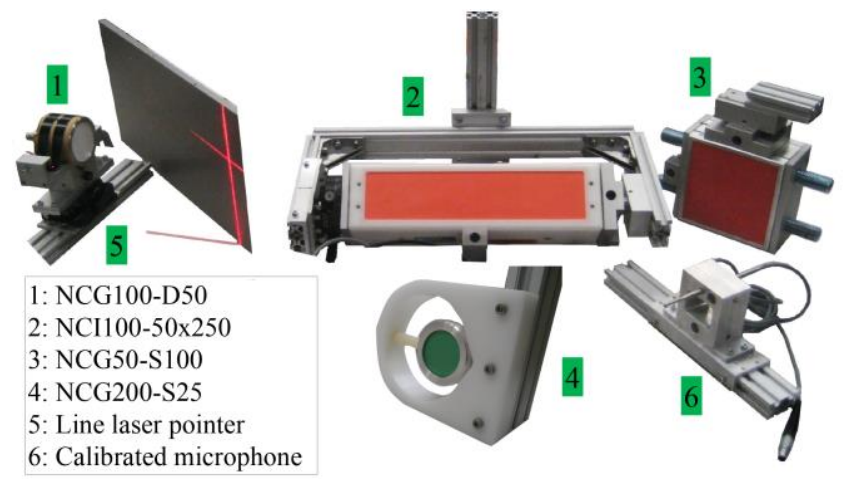

Fig. 2. Investigated ACU transducers.

TABLE I

TRANSDUCER AND SOUND FIELD SCAN PROPERTIES

\begin{tabular}{|c|c|c|c|c|}
\hline No. & Name & $\begin{array}{c}\text { Active } \\
\text { area }[\mathrm{mm}]\end{array}$ & $\begin{array}{l}\text { Freq. } \mathrm{f} \\
{[\mathrm{kHz}]}\end{array}$ & $\begin{array}{l}\mathrm{BW}_{30 \mathrm{~dB}} \\
{[\mathrm{kHz}]}\end{array}$ \\
\hline I & NCG50-S100 & $100 \times 100$ & 50 & {$[38,74]$} \\
\hline$\|^{\mathrm{a}}$ & NCG100-D50 & $\varnothing 25$ & 120 & {$[63,183]$} \\
\hline III & NCG200-S25 & $\varnothing 50$ & 230 & {$[142,282]$} \\
\hline IV & NCl100-50x250 & $50 \times 250$ & 120 & {$[67,169]$} \\
\hline No. & $\begin{array}{l}\text { INPUT X PLANE } \\
{[\mathrm{MM}]}\end{array}$ & \multicolumn{2}{|c|}{$\begin{array}{c}\text { Scan volumen } \\
X / Y / Z \\
{[\mathrm{~mm} / \mathrm{mm} / \mathrm{mm}]}\end{array}$} & $\begin{array}{l}\text { Resolution } \Delta x / \Delta y \\
/ \Delta z[\mathrm{~mm} / \mathrm{mm} / \mathrm{mm}]\end{array}$ \\
\hline 1 & 364 & \multicolumn{2}{|c|}{$400 / 250 / 400$} & $8 / 2 / 2$ \\
\hline\|\|$^{a}$ & 219 & \multicolumn{2}{|c|}{$400 / 200 / 200$} & $8 / 1 / 1$ \\
\hline III & 105 & \multicolumn{2}{|c|}{$400 / 400 / 400$} & $4 / 0.5 / 0.5$ \\
\hline IV & 219 & \multicolumn{2}{|c|}{$400 / 250 / 400$} & $10 / 1 / 10$ \\
\hline
\end{tabular}

a Additional investigated configurations: Resolution 8/0.5/0.5 and 8/2/2; Scan volume 400/400/400 (Fig. 10); Input X plane 92 and 324 (Fig. 11). 
In this work, we develop a re-radiation method for the characterization of the sound field of ACU transducers based on a reduced number of microphone measurements. We use a forward analytical solution based on the Rayleigh-Sommerfeld integral and an inverse solution based on time-reversal mirrors. This allows characterization of both the near and far fields based on measurements on a single plane with coarse discretization steps of the size of the wavelength $h \cong \lambda$. We experimentally validate our method for two-dimensional and three-dimensional ACU transducer geometries and evaluate optimum parameter sets and uncertainty sources.

\section{THEORY}

The derivation of the re-radiation equations follows [30] and [37]. An arbitrary pulsed scalar field in 3D-space $p(\mathbf{x}, t)$, where $\mathbf{x}=(x, y, z)$ and $t$ are space and time coordinates, respectively, is uniquely represented with in the spectral domain with the Fourier transform $p(\mathbf{k}, \omega)$ :

$$
p(\mathbf{k}, \omega)=\int_{-\infty}^{\infty} \iiint_{-\infty}^{\infty} p(\mathbf{x}, t) e^{-i(\mathbf{k} \cdot \mathbf{x}+\omega t)} \mathrm{d} \mathbf{x} \mathrm{d} t
$$

where $\mathbf{k}=\left(k_{x}, k_{y}, k_{z}\right)$ are wave vectors and $\omega$ harmonic components. The propagation of acoustic pressure fields $p(\mathbf{x}, t)$ in a linear incompressible medium is given by Helmhotz equation $\nabla^{2} p-c^{-1} \partial_{t}^{2} p=0$, in function of the speed of sound $c$, which in the Fourier domain writes as:

$$
\nabla^{2} p+k^{2} p=0, \quad k=\frac{\omega}{c}=\frac{2 \pi}{\lambda}
$$

where $\lambda$ is the wavelength. Substituting (1.2) in (1.1) reduces one degree of freedom in (1.1), so that $k_{x}=\left(k^{2}-k_{y}{ }^{2}-\right.$ \left.${k_{z}}^{2}\right)^{1 / 2}$ is determined:

$p\left(x, k_{y}, k_{z}, \omega\right)=\iint_{-\infty}^{\infty} p(\mathbf{x}, \omega) e^{-i\left(k_{y} y+k_{z} z\right)} e^{-i k_{x} x} \mathrm{~d} y \mathrm{~d} z$

Equation (1.3) is an angular wave spectrum model of the pressure field as a superposition of plane wavefronts forward propagating in positive direction $x$. From (1.3) it follows that the pressure field is determined by a measurement at an arbitrary plane $x=0$ (acoustic holography):

$$
p\left(x, k_{y}, k_{z}\right)=p\left(0, k_{y}, k_{z}\right) e^{-i k_{x} x}
$$

Next, a space domain representation of (1.4) is found as a superposition of spherical waves (Huygen's principle). Considering the Fourier transform pair for the free-space Green function $\quad\left(4 \pi\|\mathbf{x}\|_{2}^{2}\right)^{-1} e^{-i k\|x\|_{2}^{2}} \Leftrightarrow\left(2 i k_{x}\right)^{-1} e^{-i k_{x} x}$, the convolution property $f * g \Leftrightarrow f g$, and the linearity property $\partial_{x} g \Leftrightarrow \partial_{x} g$, the inverse transform of (1.4) is:

$$
p(\mathbf{x}, \omega)=\iint_{-\infty}^{\infty} p(0, \hat{y}, \hat{z}) g_{P S}(x, y-\hat{y}, z-\hat{z}) \mathrm{d} \hat{y} \mathrm{~d} \hat{z}
$$

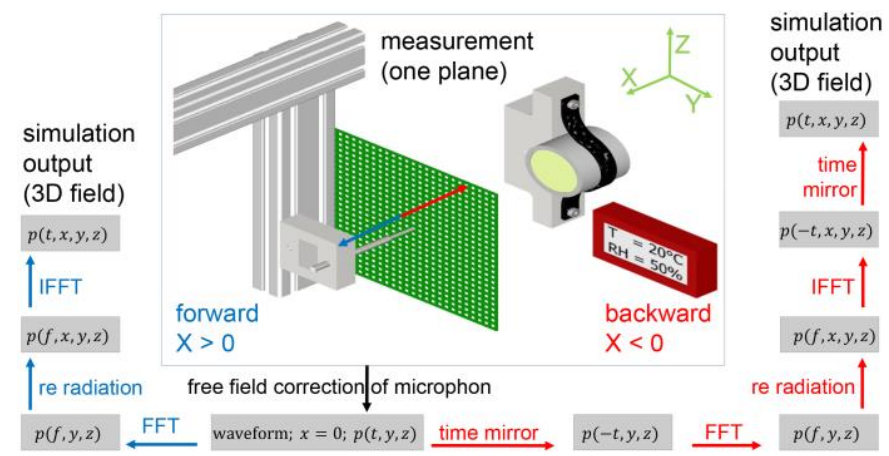

Fig. 3. Practical implementation of re-radiation algorithm. with $g_{P S}$ the point source convolution kernel:

$$
g_{P S}(\mathbf{x})=\frac{e^{-i k\left\|_{\mathbf{x}}\right\|_{2}^{2}}}{2 \pi\|\mathbf{x}\|_{2}^{2}}\left(\frac{1}{\|\mathbf{x}\|_{2}^{2}}+i k\right) \frac{x}{\|\mathbf{x}\|_{2}^{2}}
$$

Equation (1.5) is a closed expression, which allows the calculation of arbitrary $p(\mathbf{x}, t)$ given $\left.p(\mathbf{x}, t)\right|_{x=0}$. The term $\frac{1}{\|x\|_{2}^{2}}$ corresponds to inhomogeneous waves, which vanish for $\|\mathbf{x}\|_{2}^{2} \gg \lambda /(2 \pi)$, and can be neglected for the computations. At large distances from the transducer surface $\frac{x}{\|x\|_{2}^{2}} \cong 1$, and (1.5) can be expressed in time domain with:

$p(\mathbf{x}, t) \cong \iint_{-\infty}^{\infty} \frac{(2 \pi c)^{-1}}{\|\mathbf{x}\|_{2}^{2}} \partial_{t} p\left(0, y-\hat{y}, z-\hat{z}, t-\frac{\|\mathbf{x}\|_{2}^{2}}{c}\right) \mathrm{d} \hat{y} \mathrm{~d} \hat{z}$

(1.7)

which is a form of the Rayleigh-Sommerfeld integral. In a practical implementation, a discretized version of (1.5), with a finite measurement window $N_{\Sigma}$ and pixel size $h_{\Sigma}$, is used:

$p(\mathbf{x}, \omega) \cong \sum_{s=1}^{N_{\Sigma}}\left(h_{\Sigma}\right)^{2} p\left(0, \hat{y}_{s}, \hat{z}_{s}, \omega\right) g_{P S}\left(x, y-\hat{y}_{s}, z-\hat{z}_{s}\right)(1.8)$ $p\left(0, \hat{y}_{s}, \hat{z}_{s}, \omega\right)$ represents the Fourier representation of the input pressure/time waveforms $p\left(0, \hat{y}_{s}, \hat{z}_{s}, t\right)$ at the source plane $\left(\hat{y}_{s}, \hat{z}_{s}\right)$, which is approximated with the Discrete Fourier Transform (DFT).

\section{Particularization for two-dimensional pressure fields}

In the particular case of a line excitation, a homogeneous pressure field can be assumed in Z-direction and (1.8) is rewritten as:

$p(\mathbf{x}, \omega) \cong \sum_{s=1}^{N_{\Sigma}} h_{\Sigma} p\left(0, \hat{y}_{s}, \omega\right) g_{L S}\left(x, y-\hat{y}_{s}\right)$

The field of the elementary line source

$g_{L S}(x, y)$ is obtained by integrating (1.6) along Z:

$g_{L S}(x, \mathrm{y})=\int_{-\infty}^{\infty} g_{P S}(x, y, z) \mathrm{d} z=$

$-\frac{i}{2} H_{1}^{2)}\left(k \sqrt{x^{2}+y^{2}}\right) k \frac{x}{\sqrt{x^{2}+y^{2}}}$

where $H_{1}^{2)}$ is the tabulated Hankel function of order 1 and second kind.

\section{Time reversal of pressure fields}

The inversion of ultrasound waveforms through linear media is based on the time-reversal invariance of Helmhotz equation (1.2), which, due to the second-order time derivative $\partial_{t}^{2}$, is satisfied for both positive $t$ and negative $-t$ time values [9]. Recalling (1.7), if time waveforms excited by a real ACU transducer are sampled along an arbitrary cross-sectional plane and then used as excitation of the wave propagation model, the diffraction of the ultrasound beam is calculated (forward reradiation). However, if the waveforms are reversed in time $\left.p(\mathbf{x},-t)\right|_{x=0}$, the simulated waveforms propagate backwards in time converging to the transducer source excitation (backward re-radiation). Since $\mathrm{Eq}(1.5)$ is an exact integral representation of the Helmhotz equation, the time-reversal model is as well exact. $\mathrm{Eq}(1.7)$ is then rewritten as:

$$
p(\mathbf{x}, t)=\iint_{-\infty}^{\infty} \frac{(2 \pi c)^{-1}}{\|\mathbf{x}\|_{2}^{2}} \partial_{t} p\left(0, y-\hat{y}, z-\hat{z}, \frac{\|\mathbf{x}\|_{2}^{2}}{c}-t\right) \mathrm{d} \hat{y} \mathrm{~d} \hat{z}
$$

Thus, a measurement $\left.p(\mathbf{x},-t)\right|_{x=0}$ is sufficient to calculate the far field (1.7) and near field (1.11) of the 3D transducer. The same applies for the $2 \mathrm{D}$ case $(1.9,1.10)$. 


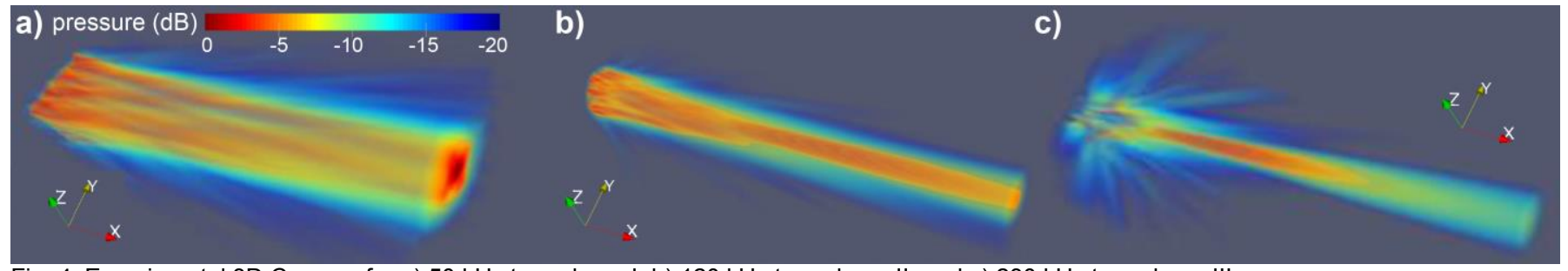

Fig. 4. Experimental 3D C-scans for a) $50 \mathrm{kHz}$ transducer I, b) $120 \mathrm{kHz}$ transducer II, and c) $230 \mathrm{kHz}$ transducer III.

\section{EXPERIMENTS}

Figure 1 illustrates the setup for measurement of ACU transducers TX. A point receiver RX is mechanically scanned with respect to the transmitter TX, and the time waveforms emitted by the TX are recorded at defined positions. This setup provides both plane measurements as input for the re-radiation equations, and sound field data for validation at arbitrary threedimensional space points. Pressure readings RX were acquired with a calibrated pressure-field microphone RX (4138, Brüel \& Kjær, Nærum, Denmark), with a sensitivity of $10 \mathrm{mV} / \mathrm{Pa}$ and a polarization voltage of $200 \mathrm{~V}$. The microphone has a diameter of $1 / 8$ ", which corresponds approx. to the wavelength in air $\lambda$ at $110 \mathrm{kHz}$, and a flat response between $6.5 \mathrm{~Hz}$ to $140 \mathrm{kHz}( \pm 2$ dB). The investigated TX, which are shown in Fig. 2, were Gas Matrix Piezoelectric Composites (GMPC, The Ultran Group Inc., State College, PA, USA) for NDE applications, which, based on proprietary multi-layer acoustic matching layers, allow efficient ACU transmission through solid samples with short pulse responses $(100-200 \mu \mathrm{s})$ [31]. The last matching layer is a compressed fiber composite, which is not adequate for laser vibrometer measurements. One square I and two circular transducers II and III were measured, with frequencies of 50, 120 and $230 \mathrm{kHz}$, respectively. This is the state-of-the-art ACU transducer technology for thick material inspection [7, 32-35]. In particular, [32] reported transmission through $200 \mathrm{~mm}$ thick concrete at $100 \mathrm{kHz}$, and [7] achieved transmission through 500 $\mathrm{mm}$ thick glued timber with both the $50 \mathrm{kHz}$ and the $120 \mathrm{kHz}$ transducers. The $230 \mathrm{kHz}$ transducer shows a frequency response, which is outside the "flat" region of the microphone, and is used to study the influence of the limited receiver bandwidth. The $\mathrm{X}$-axis is the radiation axis of the transducer, while $\mathrm{Y}$ and $\mathrm{Z}$ define cross-sections of the ultrasound beam. Additionally, a $120 \mathrm{kHz}$ rectangular transducer IV $(50 \mathrm{~mm} \times 250 \mathrm{~mm})$ was investigated, with an approximately constant pressure distribution along the longest dimension $\mathrm{Z}$, in order to simulate a two-dimensional pressure field (Fig. 1). The origin of the coordinate system is at the center of the transducer surface. Transducer specifications are summarized in Table I. The near-field distance is approximated with $N F=f D^{2} /(4 c)$, which is exact for circular transducers and provides the natural focusing distance of the transducers (a nominal value of $c=343$ $\mathrm{m} / \mathrm{s}$ is used to calculate the $N F$ estimates). The bandwidth of the transducers $\mathrm{BW}$ is defined with respect to the $30 \mathrm{~dB}$ drop from the peak response $\left(\mathrm{BW}_{-30 \mathrm{~dB}}\right)$. A $-30 \mathrm{~dB}$ transmission (3\%) with respect to the peak field value is also used in the pressure plots as a threshold level, below which the sound field variations are consider to be small.
For high-precision measurement of the three-dimensional sound pressure distribution, both $\mathrm{Tx}$ and $\mathrm{Rx}$ were attached to motorized scanning systems. For each plane acquisition, the radiation axis of Tx was first aligned with Rx. The alignment was considerably simplified by embedding two line laser pointers in the transducer holders (Fig. 2), which generated a light cross along the transducer radiation axis. The horizontality of the TX was controlled with a bubble level, as well as the parallelity of RX and TX surfaces (maximum distance error 0.5 $\mathrm{mm}$ ). Then a two-dimensional raster scan (YZ) was continuously performed with a two-axis belt drive scanning system (AB), with working distances of 500 and $780 \mathrm{~mm}$, respectively, and a positioning reproducibility of $\pm 0.2 \mathrm{~mm}$. Incremental shaft encoders connected to the spindles of the linear axes triggered the ultrasound system at the defined data acquisition steps (Table I). The scan velocity was $60 \mathrm{~mm} / \mathrm{s}$ for all acquisitions; each YZ plane data acquisition was performed in $14 \mathrm{~min}$. For the smallest grid $(0.5 \mathrm{~mm})$, the highest pulse repetition frequency (PRF) was $120 \mathrm{~Hz}$.

Dedicated software to control the five-axes scanning system and the excitation and acquisition of ACU signals was written in LabVIEW® (National Instruments Corp., Austin, TX, USA). The maximum recommended operating voltage of the GMPC transducers is $<1 \mathrm{kVpp}$. Ultrasound pulses, consisting of two sinusoidal oscillations at the operating frequency (Table I), were generated with an arbitrary waveform generator (NI PCI5421) and amplified with a High Power Tone Burst Pulser (RPR4000, RITEC Inc., Warwick, RI, USA) to an input excitation of $0.2 \mathrm{kVpp}$. The received signal level in the microphone did not exceed $1 \mathrm{~V}$, corresponding to a maximum $100 \mathrm{~Pa}$ pressure. The signals recorded by the microphone were conditioned with a built-in low-noise preamplifier, band-pass filtered according to their bandwidth and digitized at a sampling frequency of $2.5 \mathrm{MS} / \mathrm{s}$ with 14 bits resolution (NI PCI-5122).

The measured input plane $\mathrm{X}$ for the re-radiation was set to the approximate near field distance $N F$, in order to achieve simultaneously a smooth and focused beam cross section. The grid step was defined roughly as $\lambda / 3$. A smaller grid step than the microphone diameter was used to achieve over-sampling of the acoustic field, which provided a noise reduction effect and a detailed capture of the phase information. The window size was set to 4 times the transducer diameter. In the case of the rectangular transducer (IV), the $\mathrm{Z}$ coordinate was measured with coarser resolution $(10 \mathrm{~mm})$ and all $\mathrm{Z}$ lines were averaged to provide an input line excitation $(\mathrm{Y})$ to the two-dimensional re-radiation algorithm. For transducer II, special settings, such as a higher resolution $\lambda / 6$, a double window size, and input $X$ distances in both near and far field regions were additionally, in 
a)

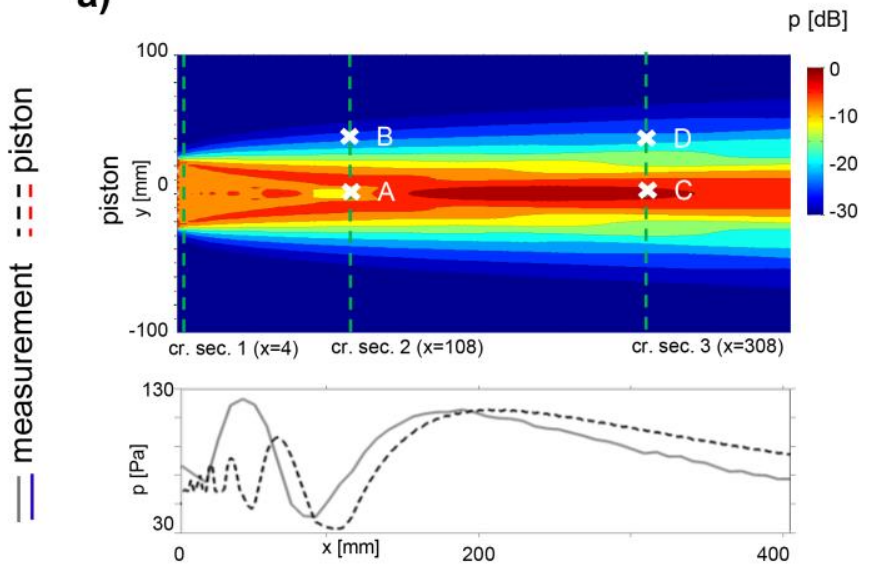

b)

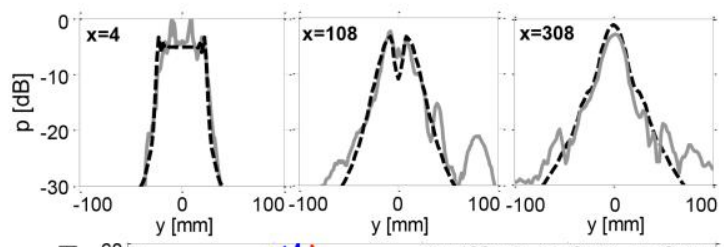

c)
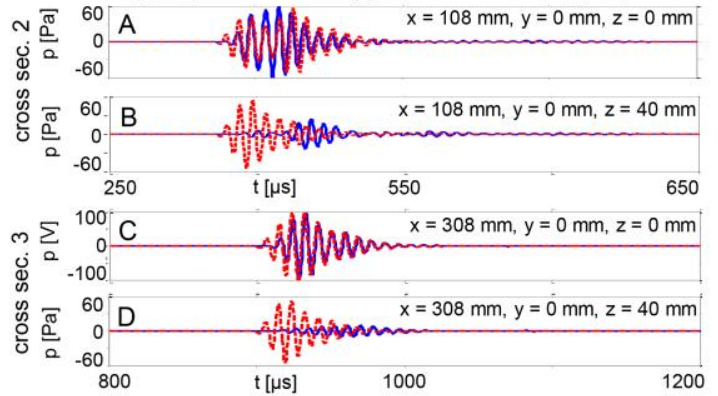

Fig. 5. Baffled piston transducer model for $120 \mathrm{kHz}$ transducer II. a) shows a C-scan of an $\mathrm{YZ}$ axial plane (for comparison with measurement data see as well Fig. 6a). b) shows C-scans for YZ beam cross-sections, c) A-scans at selected positions.

a)

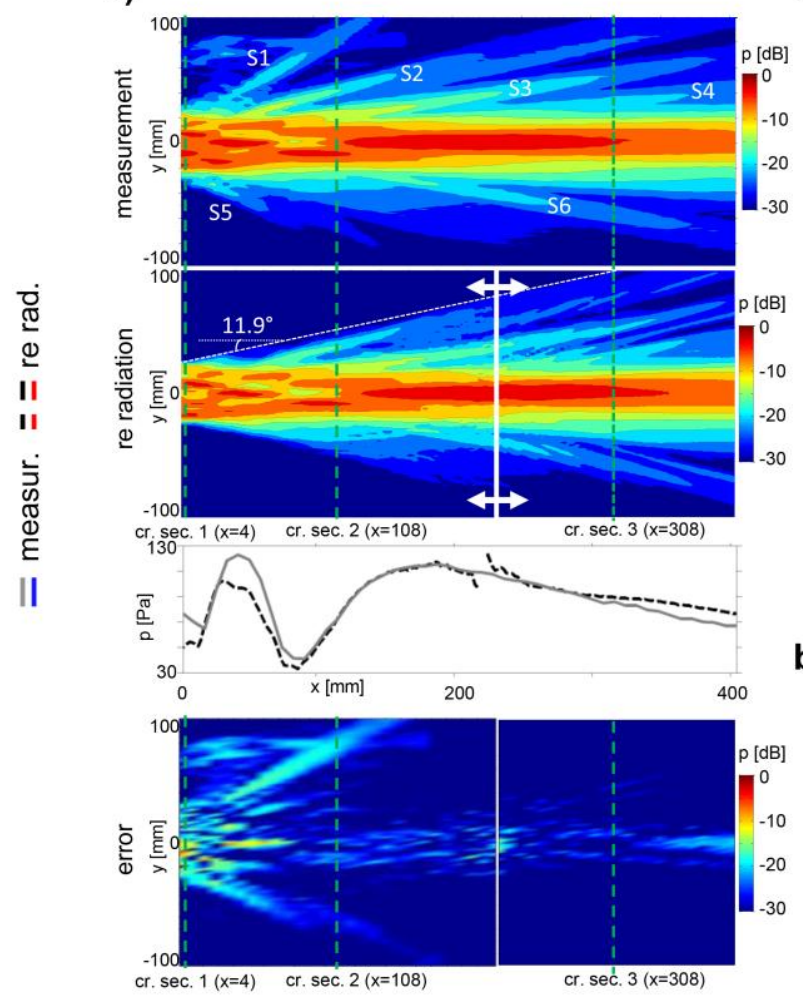

b)

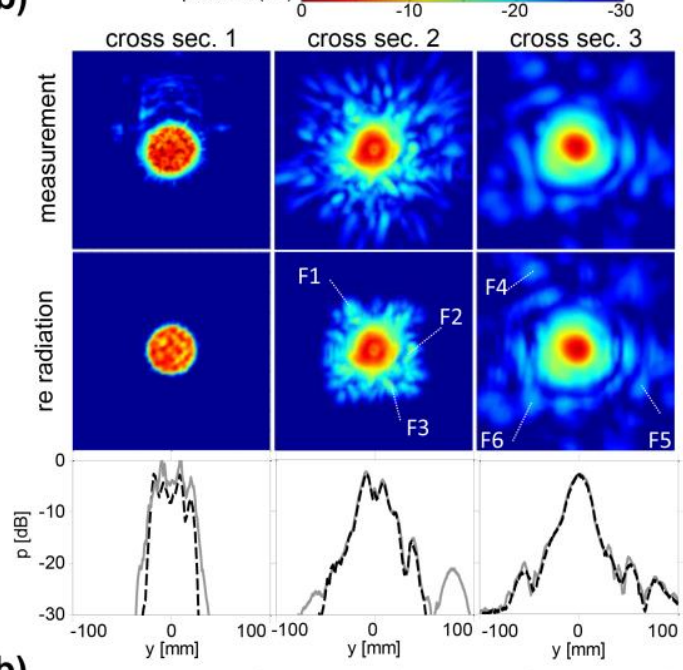

b)

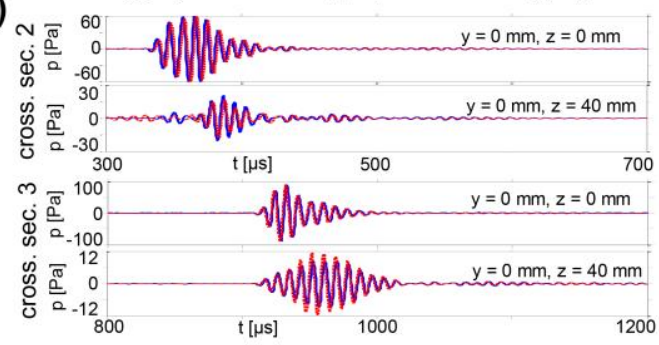

Fig. 6. Validation of 3D re-radiation algorithm for $120 \mathrm{kHz}$ transducer II. a) and b) shows C-scans for XY and YZ sections, c) selected A-scans.

order to evaluate their impact on the simulation.

As shown in the previous section, the speed of sound in air $c$ is a required parameter for the sound field reconstruction. A thermodynamics relation [44] was used to compute $c$ in function of the temperature $T\left(20-30^{\circ} \mathrm{C}\right)$ and the relative humidity $R H(20-40 \%)$. The pressure is calculated with the barometric formula and assumed to be constant. $T$ and $R H$ were recorded with a digital data logger (Ecolog TH1 2423, ElproBuchs AG, Buchs, Switzerland), with an accuracy of $\pm 0.2^{\circ} \mathrm{C}$ and $\pm 1.5 \%$, respectively. As empirically shown in [45], in room conditions $c$ can be calculated with an accuracy of $0.4 \mathrm{~m} / \mathrm{s}$. A single value of $c$ was estimated for each transducer.
The microphone receiver RX behaves as a reflector of ultrasound waves, which influences the measurement of the sound field. The presence of the microphone increases the sound pressure both in front of the microphone capsule and on the surface of the membrane. This leads to higher pressure readings than the actual field. The free- field response (without microphone) was calculated with an angle- and frequencydependent free-field correction (FFC), using the calibration plots provided by the manufacturer [11]. The angle of incidence is calculated with respect to the centers of transmitter and receiver transducer surfaces. The FFC effectively provides a deconvolution filter, which alleviates microphone distortion at 
a)
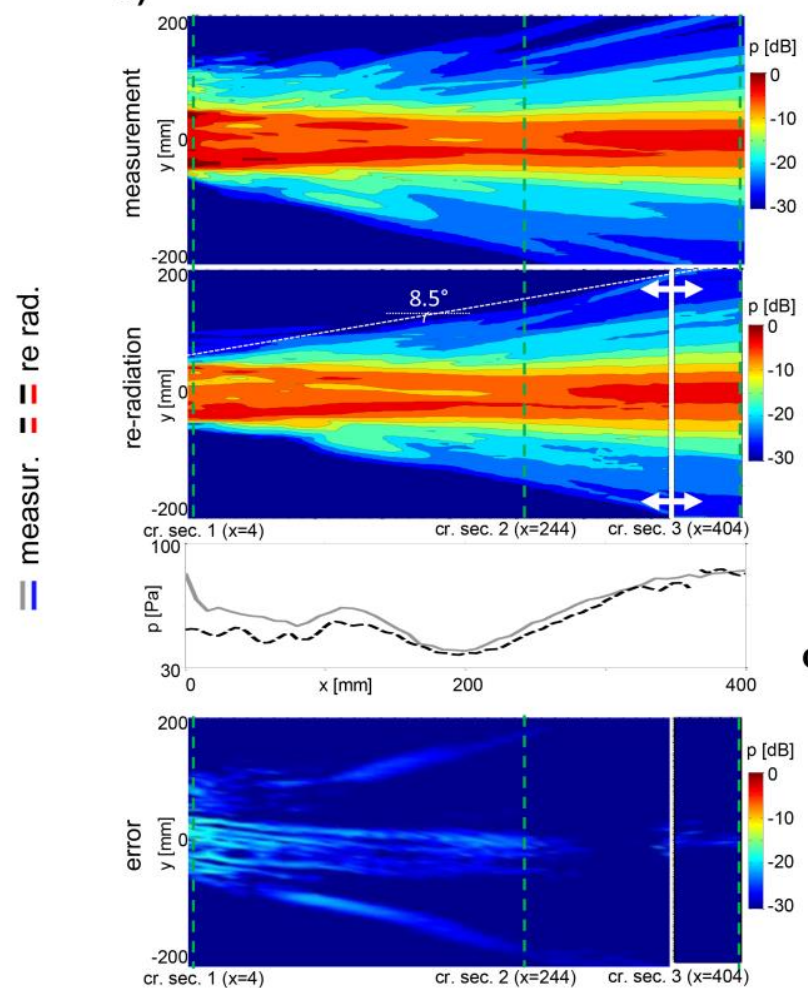

b)

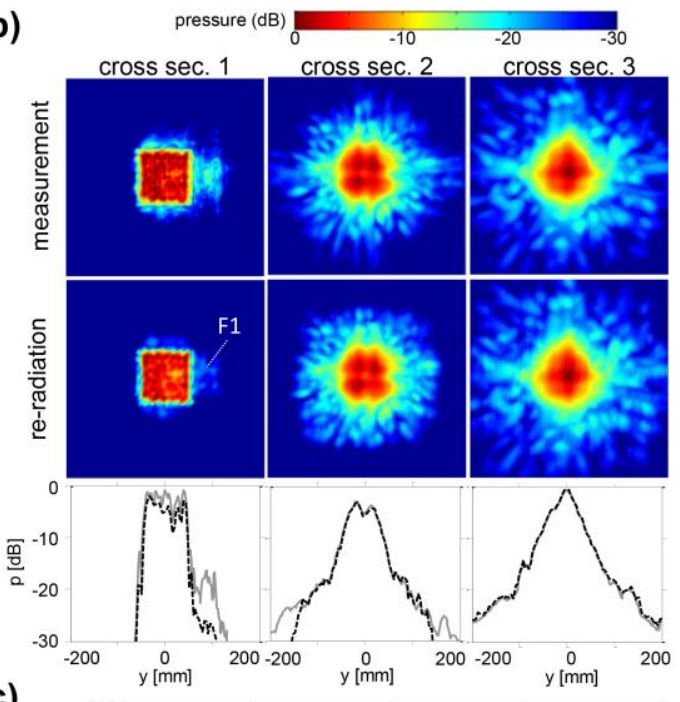

c)

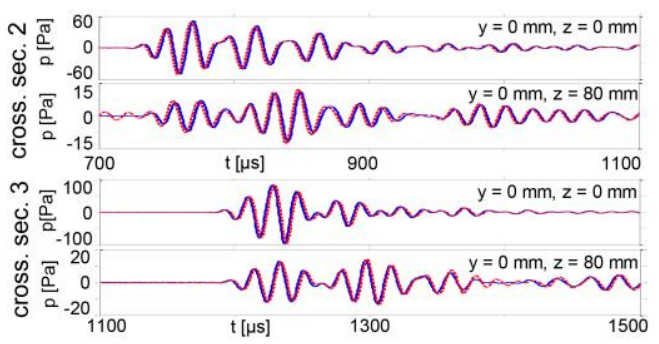

Fig. 7. Validation of 3D re-radiation algorithm for $50 \mathrm{kHz}$ transducer $\mathrm{I}$. a) and b) shows $\mathrm{C}$-scans for $\mathrm{XY}$ and $\mathrm{YZ}$ sections, c) selected A-scans.

a)

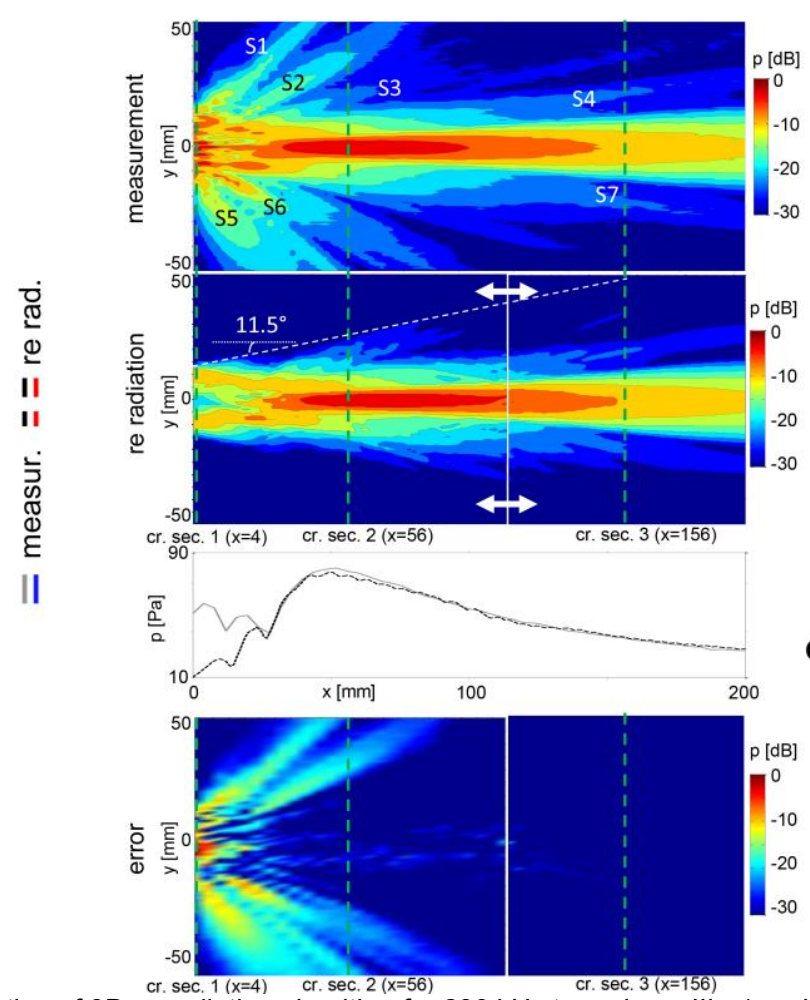

b)

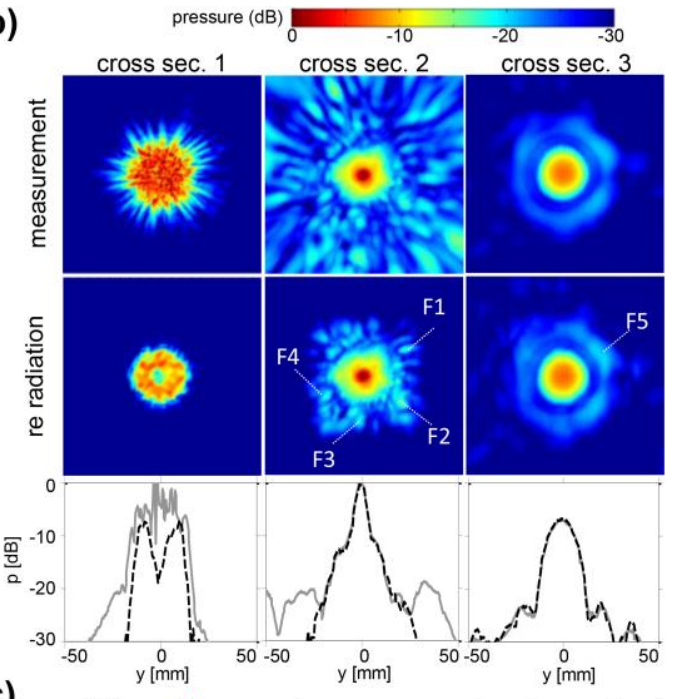

c)

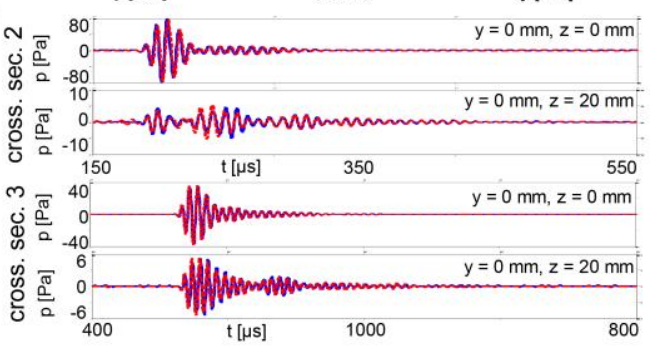

Fig. 8. Validation of 3D re-radiation algorithm for $230 \mathrm{kHz}$ transducer III. a) and b) shows C-scans for $X Y$ and $Y Z$ sections, c) selected A-scans.

high frequencies. The 4138 microphone (condenser type) is the highest frequency microphone provided by B\&K. Although calibrated only until $140 \mathrm{kHz}$, it is able to capture higher frequencies $(6 \mathrm{~dB}$ drop at $230 \mathrm{kHz})$.
After FFC correction, the pressure waveforms in the recorded $\mathrm{X}$-plane were used as input to calculate the volumetric fields $p(x, y, z, t)$. Figure 3 describes a practical version of the reradiation method described in Section II. First, the time 

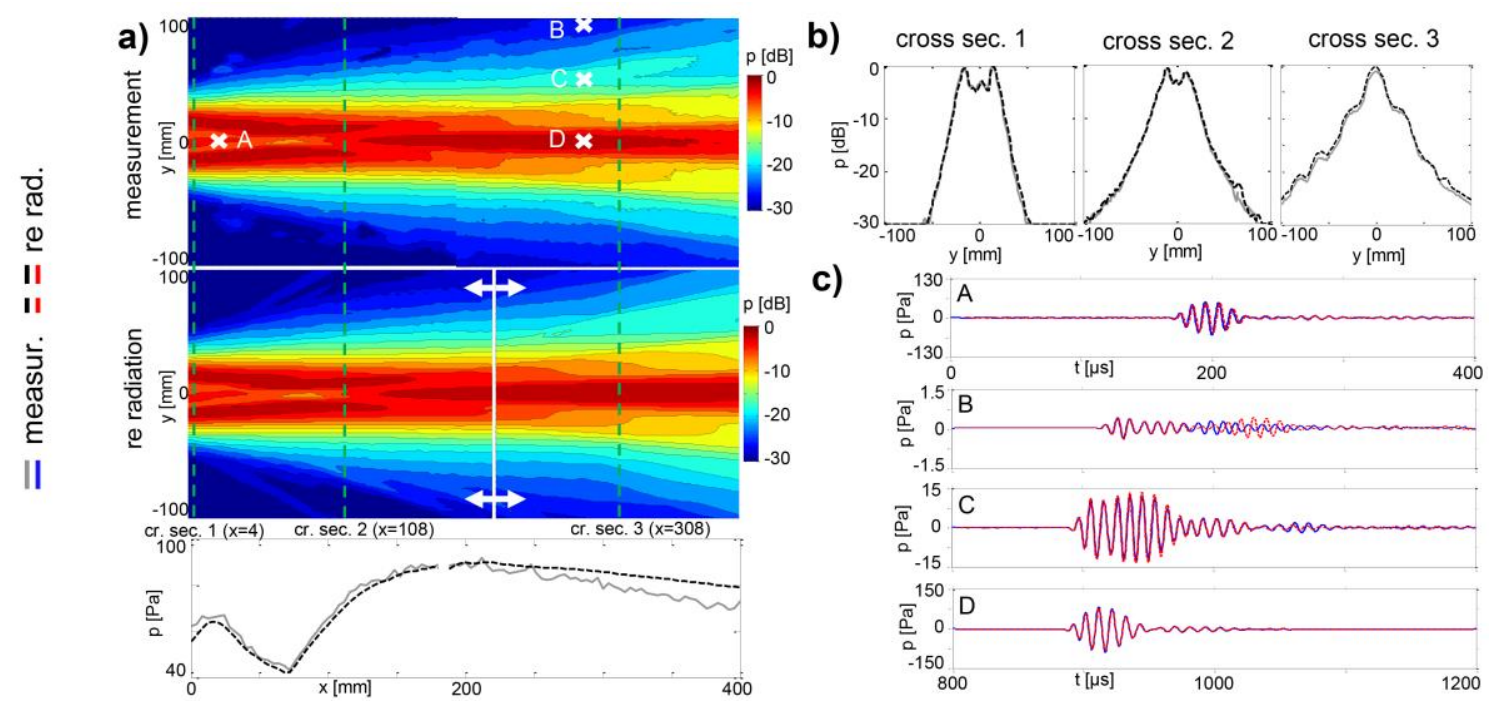

Fig. 9. Validation of 2D re-radiation algorithm for $120 \mathrm{kHz}$ transducer IV. a) and b) shows C-scans for $X Y$ and $Y Z$ sections, c) selected A-scans.

waveforms at each measured point $p(y, z, t)$ are converted to the spectral domain $p(y, z, f)$ with a Fast Fourier Transform (FFT). Then, the summations Eq. 1.8 or Eq. 1.9 are used to compute the forward re-radiation step. Finally, the frequencydependent fields $p(x, y, z, f)$ are transformed back to the time domain with an inverse FFT (IFFT) $p(x, y, z, t)$. The same procedure applies to the backward re-radiation, in which additionally the time waveforms are mirrored in time $p(x, y, z,-t)$ before the FFT step and again after the IFFT step.

As validation, the calculated pressure fields were compared to the measured volumetric pressure fields. Single time waveforms (A-scans) at specific points were plot. Amplitude images (C-scans) were generated by recording the peak value of the time waveform at each scan position, and visualized as 3D volumetric plots, 2D cross-sections or 1D profiles. A logarithmic scale representation normalized to the pressure on the furthest on-axis relative maximum (empirical definition of $N F$ distance) $p_{\max }$ was used in the plots. Pressure errors were obtained by subtracting calculated $\widehat{p}_{l}$ and measured $p_{i}$ pressure values and were represented in the same logarithmic scale. The root mean square error (rmse) and the maximum pressure deviation (MaxDev) were respectively calculated as:

rmse $=\sqrt{N^{-1} \sum_{i=1}^{N}\left(p_{i}-\widehat{p}_{\imath}\right)^{2} / p_{\text {max }}^{2}}$

$\operatorname{maxDev}=\max \left|p_{i}-\widehat{p}_{l}\right| / p_{\max }$

For maxDev a median filter was applied to $p_{i}-\widehat{p}_{l}$ to avoid one pixel mis-registration errors. All calculations were performed in Matlab ${ }^{\circledR}$ software (The Mathworks Inc., Natick, MA, USA).

\section{RESULTS AND DISCUSSION}

Figure 4 shows 3D C-Scans of the measured volumetric fields for the transducers I $(50 \mathrm{kHz})$, II $(120 \mathrm{kHz})$ and III (230 $\mathrm{kHz}$ ). Due to the large ratio between active diameter and wavelength $D / \lambda \cong 17$, all transducers show a good collimation, with a $6 \mathrm{~dB}$ beamwidth at $X=400 \mathrm{~mm}$ of $76 \mathrm{~mm}$, $34 \mathrm{~mm}$ and $24 \mathrm{~mm}$, respectively. The near field distances $N F$, defined as the distance of the furthest relative pressure maxima are found at $410 \mathrm{~mm}, 172 \mathrm{~mm}$ and $56 \mathrm{~mm}$. The differences with the $N F$ estimates in Table I are associated to both deviations from the cylindrical geometry and the pulsed response of the transducer. The experimental pressure distribution is not perfectly axisymmetric, due to imperfections in the transducer matching layers. Moreover, in the measurements the number of side lobes also strongly increase with the frequency, probably due to wave scattering effects at the transducer matching layers and surface edges.

Figure 5 shows a baffled piston model of the $120 \mathrm{kHz}$ transducer II, according to prior state of the art [14, 26, 27]. In this case, the excitation plane $\mathrm{X}$ for Eq 1.8 corresponds to the radiation surface of the transducer, which is described with a constant vibration inside the circular transducer surface and no vibration outside. The measured transducer pulse response onaxis at the $N F$ distance was used to estimate the pulsed time waveform at the transducer surface, and the calculated pressure fields was normalized to match the experimental data at $N F$ distance. Contrary to experimental data (Fig. 6a), this setup leads to an axially symmetric field distribution (Fig. 5a). Normalized cross-beam profiles (Fig. 5b) show a good agreement with experimental data at the $-6 \mathrm{~dB}$ level, which corresponds to the main beam lobe. As a consequence, the rmse of the beam width for the forward re-radiation (far field, $\mathrm{X}>$ $N F$ ) is only $0.3 \mathrm{~mm}$. However, the piston model fails to reproduce side lobes, leading to a large rmse of $9 \mathrm{~mm}$ at $-20 \mathrm{~dB}$ level. Together with the symmetry of the baffled piston, the

TABLE II

SOUND FIELD PREDICTION ERROR

\begin{tabular}{ccccc}
\hline \hline No. & $\begin{array}{c}\text { RMSE } \\
\text { FORWARD } \\
(\%)\end{array}$ & $\begin{array}{c}\text { MAX DEV } \\
\text { FORWARD } \\
(\%)\end{array}$ & $\begin{array}{c}\text { RMSE } \\
\text { BACKWARD } \\
(\%)\end{array}$ & $\begin{array}{c}\text { MAXDEV } \\
\text { BACKWARD } \\
(\%)\end{array}$ \\
\hline I & 1.3 & 4.3 & 3.2 & 12 \\
II & 2.2 & 9.7 & 5.4 & 21 \\
III & 1.1 & 3.2 & 9.3 & 50 \\
IV & 2.4 & 11 & 2.0 & 13 \\
\hline \hline
\end{tabular}

RMSE: root mean square error, MAX DEV: maximum deviation 

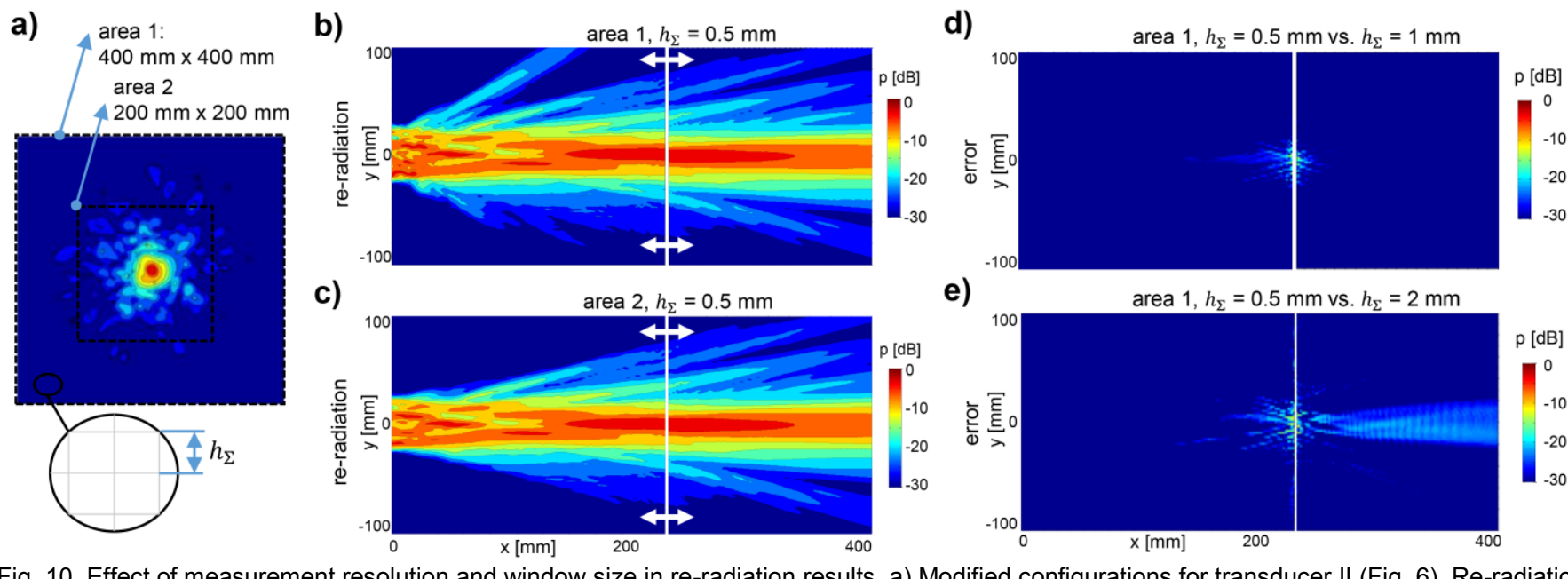

Fig. 10. Effect of measurement resolution and window size in re-radiation results. a) Modified configurations for transducer II (Fig. 6). Re-radiation results (C-scans in XY plane) are calculated with high resolution (measured pixel size $\boldsymbol{h}_{\boldsymbol{\Sigma}}=0.5 \mathrm{~mm}$ ) for b) double-size and c) normal size areas. Amplitude errors are shown between b) and two coarser resolutions c) $\boldsymbol{h}_{\Sigma}=1 \mathrm{~mm}$ and d) $\boldsymbol{h}_{\Sigma}=2 \mathrm{~mm}$.
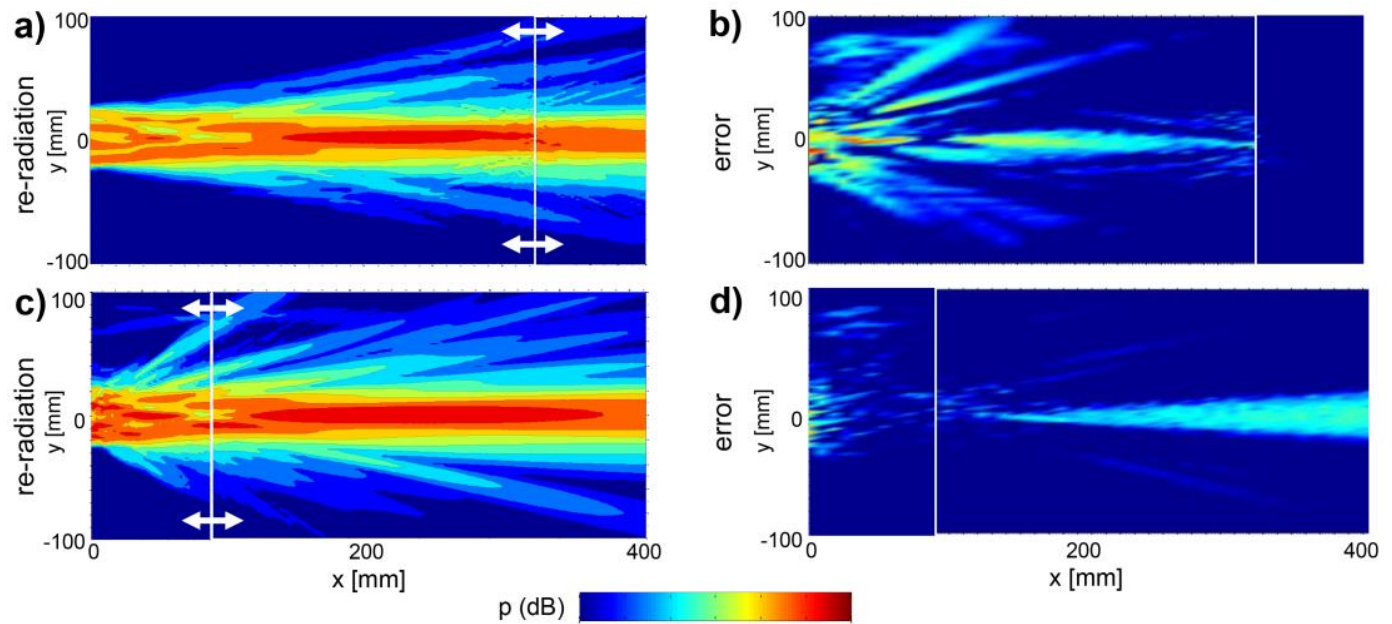

$-30 \quad-20 \quad-10 \quad 0$

Fig. 11. Effect of input $X$ plane in re-radiation results. Modified configurations for transducer II (Fig. 6) are calculated. a) and c) show C-scans calculated from measurements at $X=92 \mathrm{~mm}$ and $X=324 \mathrm{~mm}$. b) and d) respectively show errors with respect to measurement data.

pulsed transducer response acts like a spatial filter, which cancels side lobes in the simulation. Significant deviations are as well observed between the quantitative pressure values in the axial plane YX (Fig. 5), with a rmse of $4.7 \%$ in the far-field and $\operatorname{maxDev}=14 \%$. The deviations are even larger in the near-field $($ rmse $=8.7 \%$, maxDev $=54 \%)$, where the symmetry of the piston leads to an oscillatory pattern. Pulsed time waveforms (Fig. 5c) show a coarse agreement on-axis (A and C), and are poorly described at off-axis positions (B and D). Similar observations are extracted for transducer I and III (not shown).

Figure 6 to 9 compare results of the proposed re-radiation algorithm to the experimental volumetric fields for transducers I, II, III and IV. A significant predictive improvement is visually evident for the re-radiation results with respect to the piston model of Fig. 5. Re-radiation results show a close agreement to experimental data for the axial plane XY (Fig. 68a) and beam-cross sections (Fig. 6-8b). Time waveforms at both on-axis and off-axis positions are accurately reproduced (Fig. 6-8c). Non-axisymmetric field distributions and side lobes are satisfactorily reproduced. For instance, while the rmse of the beam width at $-6 \mathrm{~dB}$ for transducer I is only slightly better than the piston calculation $(0.2 \mathrm{~mm})$, the rmse at $-20 \mathrm{~dB}$ is a magnitude order smaller $(1.1 \mathrm{~mm})$. Similarly, the rmse and maxDev values of the pressure fields (Table II) are significantly reduced with respect to the piston model.

Next, the re-radiation results for each transducer are analyzed in detail, and deviations with respect to experimental data are identified. The $120 \mathrm{kHz}$ transducer II shows in the $\mathrm{YZ}$ plane (Fig. 6a) six side lobes (S1-6) above $-20 \mathrm{~dB}$ level, four for $\mathrm{Y}>0$ and two for $\mathrm{Y}<0$. The re-radiation model correctly models four side lobes (S2, S3, S4 and S6) but fails two reproduce the two closest to the transducer surface (S1 and S5). Contrary to Fig. $5 \mathrm{a}$, the axial profile of the re-radiation model Fig. 6a reproduces the near field trend, with a positive maximum at $X=42 \mathrm{~mm}$ and a negative maximum at $X=82 \mathrm{~mm}$. Pressure deviations are largest on-axis, with MaxDev $=21 \%$ for forward re-radiation and $9.7 \%$ for backward re-radiation (near field, $\mathrm{X}<N F$ ). A pressure error increase is observed in an interval of $\pm 15 \mathrm{~mm}$ from the excitation plane $(\mathrm{X}=220 \mathrm{~mm})$, approximately equivalent to $\pm 5 \lambda$. The simulated beam cross-sections (Fig. 6b) 
a)
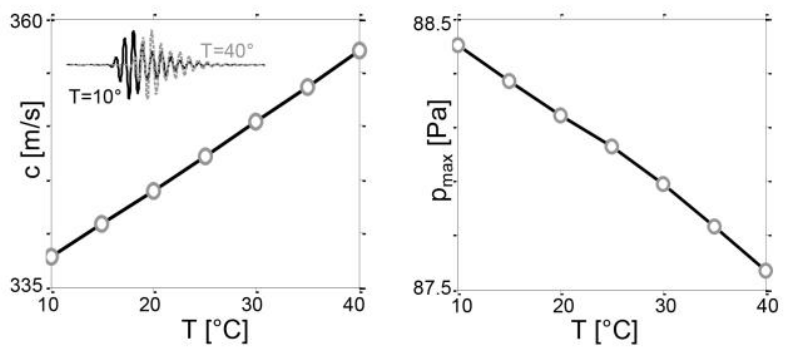

b)

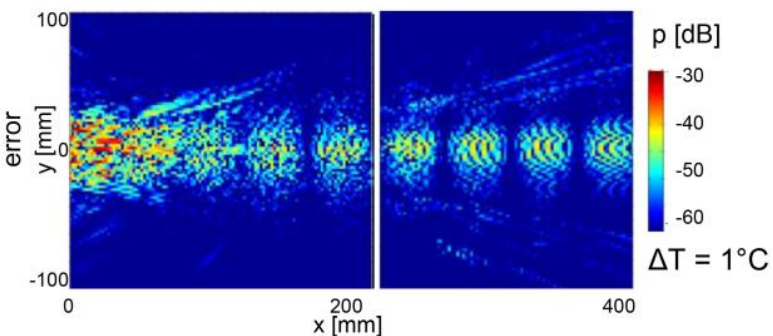

Fig. 12. Effect of temperature $T$ in re-radiation results. a) Speed of sound $c$ and maximum pressure $p_{\max }$ variations for transducer II in function of temperature. b) Comparison of re-radiation results (C-scan in XY plane) computed with nominal $\mathrm{T}$ and with a temperature shift $\Delta \mathrm{T}$ of $1^{\circ} \mathrm{C}$.

show a high level of detail, and asymmetric features above -20 $\mathrm{dB}$ are well reproduced (note for instance features F1 to F6). However, for the re-radiation results, a pressure drop is observed below experimental measured values for large offaxis distances. The distance threshold for a $-30 \mathrm{~dB}$ drop is empirically described by a truncated cone surface defined by the transducer active area and cone semi-angle of $11.7^{\circ}$. Consequently, while for cross-section $3(X=308 \mathrm{~mm})$ the full $200 \mathrm{~mm} \times 200 \mathrm{~mm}$ measurement window can be reproduced, for section $2(X=108 \mathrm{~mm})$ only a diameter of $110 \mathrm{~mm}$ matches experimental data, this area being reduced at section $1(\mathrm{X}=4$ $\mathrm{mm}$ ) to the $50 \mathrm{~mm}$ transducer active diameter. Since side lobes S1 and S5 fall outside this distance threshold, they are not reproduced. In comparison, the re-radiation results for the 50 $\mathrm{kHz}$ transducer I (Fig. 7) show a smaller cone semi-angle of $8.5^{\circ}$, which, together with the better transducer collimation, allows for a more accurate representation of the near field. Even pressure feature $\mathrm{F} 1$ outside the radiation surface at cross. section $1(\mathrm{X}=4 \mathrm{~mm})$ is captured by the model, although at a lower amplitude level. The pressure error is overall reduced by $50 \%$ with respect to transducer II (Table II). As for the $230 \mathrm{kHz}$ transducer (Fig. 8), the cone semi-angle is of $11.5^{\circ}$. Out of the seven side lobes S1-S7 observed, only the ones in the far field S3, S4 and S7 can be reproduced. Close to the transducer's radiation surface, the backward re-radiation appears somewhat smoothed with respect to experimental data, with a rmse of $9.3 \%$. This may be explained by the bandwidth of the transducer being outside the flat response of the microphone. For instance, due to the low-pass filtering effect of the microphone, in the case of transducer III the effective $20 \mathrm{~dB}$ bandwidth was $[120,210 \mathrm{kHz}]$. However, the pressure deviation in the far field are smaller than for transducer I and II, with a rmse of $1.1 \%$. Similarly, while YZ cross-sections 2 and 3 accurately reproduce asymmetric features $\mathrm{F} 1$ to $\mathrm{F} 5$ within the cone surface, cross-section 1 shows high-frequency spatial variations, which are not captured by the re-radiation model.

Figure 9 shows results for the rectangular $120 \mathrm{kHz}$ transducer IV. Due to the large aspect ratio between $\mathrm{Z}$ and $\mathrm{Y}$ dimensions $(250 / 50=5)$, the $2 \mathrm{D}$ re-radiation model described in Eq 1.9. provides an accurate representation of the average field in the YX plane. The Z-averaging produces a well-collimated field without significant side lobes, which resembles the simulated piston model in Fig. 5. The pressure deviations for the backward re-radiation are therefore significantly reduced (rmse $=2.0 \%$ ) with respect to the $3 \mathrm{D}$ transducer II ( $\mathrm{rmse}=5.4 \%$, Table II). However, a systematic deviation is observed in the far field, with the 2D model underestimating the pressure drop with distance $\mathrm{X}(\mathrm{MaxDev}=11 \%)$. This deviation can be explained by the true 3D nature of the IV transducer: a 3D point source (Eq 1.6) at large distances $r$ from the radiation surface scales the radiated power over a sphere, with $g_{P S} \propto 1 / r$. A 2D point source (Eq 1.10), on the other hand, scales over a cylinder, with $g_{L S} \propto 1 / \sqrt{r}$, thus the smaller pressure drop.

The pressure drop outside the cone semi-angle is caused by the finite size of the measurement window. This is shown in Fig. 10 by comparing re-radiation results for transducer II for the re-radiation window defined in Table I with results for a double-size re-radiation window. While the additional window region contains only small pressure values $(<-25 \mathrm{~dB})$, their cumulative effect lead to significant differences in the near field (Fig. 10b-c). Particularly, side lobes S1 and S5, which are not visible for the normal window size, can be reproduced with the double window size, due to the larger cone semi-angle $\left(>27^{\circ}\right)$.

Figure 10d-e shows the effect in the re-radiation results of different grid steps in the measured input plane. The chosen grid step $\lambda / 3$, with $h_{\Sigma}=1 \mathrm{~mm}$ for the $120 \mathrm{kHz}$ transducer appears to be a good compromise between measurement effort and accuracy. Smaller steps $\left(h_{\Sigma}=0.5 \mathrm{~mm}\right.$, Fig. 10d) do not introduce significant variations $(\mathrm{rmse}=1.0 \%$ ), except for a small $\pm 15 \mathrm{~mm}$ on-axis region close to the re-radiation plane ( $\operatorname{maxDev}=11 \%$ ), which corresponds to the $\pm 5 \lambda$ interval of onaxis uncertainty observed in Fig. 6. For a coarser grid step $\left(h_{\Sigma}=\right.$ $2 \mathrm{~mm}$, Fig. 10e), the on-axis uncertainty region increases $( \pm 30$ $\mathrm{mm}$ ), with $\mathrm{MaxDev}=17 \%$. Moreover, a significant error is observed on-axis for forward re-radiation, with rmse $=2.9 \%$. However, for backward re-radiation, no significant deviations are observed. These results can be interpreted considering that $h_{\Sigma}$ is equivalent to the active surface of the elementary sources. The larger $h_{\Sigma}$ the more directive the elementary sources become, introducing off-axis deviations with respect to the assumed ideal point source function $g_{P S}$ in Eq 1.8. The effect is most significant close to the re-radiation plane, where the elementary sources mostly contribute in off-axis directions. The results also suggest that modeling a diverging field (forward reradiation) requires a finer sampling than a focused field (backward re-radiation).

Figure 11 investigates for transducer II the effect of the reradiation plane distance $\mathrm{X}$ on the modeled field. While a larger $\mathrm{X}$ distance (Fig. 11a-b) improves the prediction performance in the far field (forward re-reradiation), on the contrary it leads to larger errors in the near field. A smaller X distance (Fig. 11c-d) 


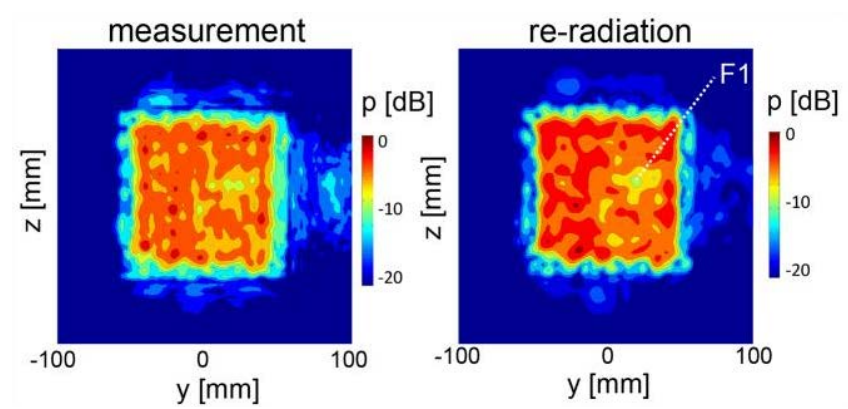

Fig. 13. Detail of experimental and simulated sound field for transducer $\mathrm{I}$ at transducer radiation surface (cross-section 1 of Fig. 7). A pressure inhomogeneity (feature $\mathrm{F} 1$ ) is visible in both $\mathrm{C}$-scans.

is on the other hand able to improve the near-field predictions (sidelobes $\mathrm{S} 1$ and S5 can be reproduced), but leads to a significant error increase in the far-field ( $r m s e=3.5 \%)$. The choice of $X$ roughly at near field distance $N F$ (Fig. 6) appears to be a good compromise. Alternatively, acquisition of several re-radiation planes at different $\mathrm{X}$ may be considered if a higher accuracy is required.

Next, uncertainty sources with smaller contributions than the ones outlined above, with pressure values $<-30 \mathrm{~dB}$, are briefly summarized. The free-field correction (FFC) for the microphone lead to small variations $(\mathrm{rmse}=0.4 \%$ ) in the modeled fields, with respect to the fields calculated without FFC. The simplifications applied in Eq 1.7 with respect to Eq. 1.5 also introduced small pressure field variations ( $\mathrm{rmse}=$ $0.3 \%)$. The effect of the climatic conditions in the estimated speed of sound $c$ is shown in Fig. 12. Based on temperature and relative humidity measurements, a $0.4 \mathrm{~m} / \mathrm{s}$ accuracy in $c$ estimation has been observed at room temperature conditions [45]. Moreover, an average $\mathrm{T}$ and $\mathrm{RH}$ readings varied by $0.1^{\circ} \mathrm{C}$ and $0.8 \%$ during a single measurement plane acquisition, and by $1^{\circ} \mathrm{C}$ and $8 \%$ over a $10 \mathrm{~h}$ volumetric scan. The corresponding $c$ variation is $0.8 \mathrm{~m} / \mathrm{s}$ for the volumetric scan and negligible for the single plane measurement $(0.08 \mathrm{~m} / \mathrm{s})$. Fig $12 \mathrm{~b}$ shows the pressure error for transducer II for a temperature variation of $1{ }^{\circ} \mathrm{C}$. The amplitude errors are small, with a rmse $=0.3 \%$. The uncertainties are largest for backward re-radiation $(\mathrm{MaxDev}=$ $2 \%$ ), where time shifts due to $c$ variations induce slight modifications of the near field interference patterns. Even for a large temperature range of 10 to $40^{\circ}(5.8 \%$ variation of $c)$, the variations of the maximum pressure are $<1 \%$ (Fig. 12a). $c$ variations also lead to time shifts in the simulated A-scans. In particular, at $200 \mathrm{~mm}$ distance from the re-radiation plane, a uncertainty in $c$ of $0.4 \mathrm{~m} / \mathrm{s}$ leads to a timing uncertainty of 0.66 $\mu \mathrm{s}$, corresponding to $8 \%$ of the oscillation period at $120 \mathrm{kHz}$. Therefore, as also shown in the A-scans from Fig. 6 to Fig. 9, for most applications the timing uncertainties are negligible. If necessary, a more accurate $c$ estimate may be obtained by explicitly measuring the time delays of the A-scans at different distances $\mathrm{X}$ and consequently performing a linear fit of $c$.

It has been previously shown [43] for water-immersed ultrasound probes that a characterization of transducer near field defects based on a far field measurement is possible with acoustic holography. This also avoids the challenges of pressure measurements directly at the transducer surface, such as microphone reverberations, or difficulties to characterize surface vibration with a laser vibrometer for heterogeneous composite layers. Given the re-radiation accuracy results, a similar potential is available for ACU transducers. For instance, Figure 13 shows a detail of the backward re-radiation of transducer I at $4 \mathrm{~mm}$ from the transducer radiation surface. This is a sub-wavelength separation and therefore the measured fields approximate well the vibration of the transducer surface. A pressure inhomogeneity $\mathrm{F} 1$, corresponding to a $12 \mathrm{~dB}$ pressure drop, was observed in both measured and simulated Cscans. This may be an indicator of a fabrication defect in transducer I, for instance, a slight misadjustment of the GMPC air matching layers.

\section{CONCLUSIONS AND OUTLOOK}

This work provides an efficient implementation of acoustic holography for air-coupled ultrasound transducers, which paves the way for the development of ACU tomography and full-wave inversion problems for quantitative ACU imaging.

The proposed re-radiation method provides a time-efficient approach for the characterization of the volumetric pressure fields of ACU transducers. A single plane measurement acquisition presently requires $<15 \mathrm{~min}$. The scan velocity may be increased at the cost of a higher PRF, which increases the presence of phantom echoes, i.e., late spurious ultrasound echoes originated in previous trigger periods. In terms of computational load, with the defined sampling strategy, for a transducer of diameter $D$ and frequency $f$, a total of $(12 D / \lambda)^{2}$ multiplications $\left(4 \cdot 10^{4}\right.$ for transducer II) are necessary per calculated coordinate and frequency. A real time implementation was out of the scope of this work. However, Eq 1.8 is fully parallelizable in terms of elementary sources, calculated coordinates and pulse frequencies. Based on stateof-the-art multi-core technologies (e.g. Graphical Processing Units - GPUs), the computation of the re-radiation results is feasible in parallel with data acquisition [46].

We provide a closed-form solution, which allows direct calculation of the field at selected coordinates. In comparison, numerical methods as FEM or FDTD require discretization of the full computational domain between transducer and receiver position and are susceptible to numerical dispersion, which accumulates with the distance. For instance, we have previously observed [24] that a discretization step of $\lambda / 40$ or less is necessary to neglect numerical dispersion in FDTD sound field calculations. The choice of a planar re-radiation surface follows practical scanning considerations. In general, other surfaces (e.g., spherical or cylindrical) may be used, as long as the forward re-radiation region does not contain any sources [20].

In this work we have focused on microphone measurements, which are adequate for characterization of NDE transducers up to $200 \mathrm{kHz}$. For the MHz range other non-contact sensing approaches, are required, such as optic methods or micromachined transducers $[12,14]$. The re-radiation model allows computation of volumetric fields as long as both the phase and amplitude of the pressure field, or a related quantity, can be measured with sufficient resolution over a two-dimensional 
spatial domain.

We have validated our method for planar transducers. Additional experimental work is needed to show the applicability of the method for focused, curved and array transducer configurations. However, the presented GMPC transducers show heterogeneous and feature-rich fields with respect to simple piston models, which are accurately described by our method, and give confidence on the generality of the proposed approach. We have shown a significant agreement between measured and predicted ACU fields at subwavelength distance from the transducer surface. An additional interesting test would be to compare re-radadiation results with direct measurements of the transducer surface displacement. Although this test was not possible for GMPC transducers due to their special matching layers, it can be done for other promising ACU transducer technologies, for instance [33, 47].

Our model effectively calculates sound field features, which deviate from the ideal piston behavior. These are indirectly related to transducer imperfections, for instance, due to problems in fabrication. Our method provides a detailed fullwave characterization of real probes, which allows their use in quantitative wave propagation models. Moreover, our method can be used in combination with a control algorithm to dynamically adjust the fabrication process variables to comply with a set of ideal transducer specifications, for instance, for a baffled piston. Apart from NDE applications, our method is relevant for medical applications, for instance, recent works for chronic wounds or the cornea based on ACU [48, 49], for which an accurate characterization of the radiation fields is critical for clinical certification.

\section{REFERENCES}

[1] D. Chimenti, "Review of air-coupled ultrasonic materials characterization," Ultrasonics, vol. 54, pp. 1804-1816, 2014.

[2] D. K. Hsu, "Non-destructive testing using airborne ultrasound," Ultrasonics, vol. 44, no. c109-c1024, 2016.

[3] D. A. Hutchins, and A. Neild, "Airborne ultasound transducers," Ultrasonic transducers: materials and design for sensors, actuators and medical applications, K. Nakamura, ed., Oxford: Woodhead Publishing, 2012.

[4] T. H. Gan, D. A. Hutchins, D. R. Billson, and D. W. Schindel, "Highresolution, air-coupled ultrasonic imaging of thin materials," IEEE Trans Ultrason Ferroelectr Freq Control, vol. 50, no. 11, pp. 1516-1524, Nov, 2003.

[5] S. P. Kelly, R. Farlow, and G. Hayward, "Applications of through-air ultrasound for rapid NDE scanning in the aerospace industry," IEEE Trans Ultrason Ferroel Freq Control, vol. 43, no. 4, pp. 581-591, 1996.

[6] I. Solodov, K. Pfleiderer, H. Gerhard, S. Predak, and G. Busse, "New opportunities for NDE with air-coupled ultrasound," NDT E Int, vol. 39, no. 3, pp. 176-183, 2006.

[7] S. Sanabria, R. Furrer, J. Neuenschwander, P. Niemz, and U. Sennhauser, "Air-coupled ultrasound inspection of glued laminated timber," Holzforschung, vol. 65, pp. 377-387, 2011.

[8] O. Michailovich, and A. Tannenbaum, "Blind deconvolution of medical ultrasound images: a parametric inverse filtering approach.," IEEE Trans on Image Process, vol. 16, no. 12, pp. 3005-3019, 2007.

[9] M. Fink, D. Cassereau, A. Derode, C. Prada, P. Roux, M. Tanter, J. L. Thomas, and F. Wu, "Time-reversed acoustics. ," Rep Prog Phys, vol. 63, no. 12, pp. 1933-1995, 2000.

[10] F. Natterer, and F. Wubbeling, "A propagation backpropagation method for ultrasound tomogaphy. ," Inverse Problems vol. 11, no. 6, pp. 12251232,1995

[11] M. Hoffmann, A. Unger, M. C. Ho, K. K. Park, B. T. Khuri-Yakub, and M. Kupnik, "Volumetric Characterization of Ultrasonic Transducers for
Gas Flow Metering," 2013 IEEE International Ultrasonics Symposium (IUS), pp. 1307-1310, 2013.

[12] B. Fischer, "Optical microphone hears ultrasound," Nature Photonics, vol. 10 , pp. 356-358, 2016.

[13] G. T. Clement, H. Nomura, H. Adachi, and T. Kamakura, "The feasibility of non-contact ultrasound for medical imaging," Phys Med Biol, vol. 58, no. 18 , pp. $6263-78,2013$.

[14] A. Neild, D. A. Hutchins, T. J. Robertson, L. A. Davis, and D. R. Billson, "The radiated fields of focussing air-coupled ultrasonic phased arrays," Ultrasonics, vol. 43, no. 3, pp. 183-95, 2005.

[15] M. Almqvist, A. Holm, H. W. Persson, and K. Lindstrom, "Characterization of air-coupled ultrasound transducers in the frequency range $40 \mathrm{kHz}-2 \mathrm{MHz}$ using light diffraction tomography," Ultrasonics, vol. 37 , no. 8 , pp. $565-575,2000$.

[16] M. J. Hargather, G. S. Settles, and M. J. Madalis, "Schlieren imaging of loud sounds and weak shock waves in air near the limit of visibility," Shock Waves, vol. 20, no. 1, pp. 9-17, 2009.

[17] R. Malkin, T. Todd, and D. Robert, "Quantitative imaging of acoustic reflection and interference," 13th Anglo-French Physical Acoustics Conference (Afpac2014), vol. 581, 2015.

[18] T. Marhenke, J. Twiefel, and J. Hasener, "Field visualization of transient ultrasound fields on panels based on the refracto-vibrometry," TmTechnisches Messen, vol. 83, no. 10, pp. 580-592, 2016.

[19] C. Trillo, A. F. Doval, S. Hernández-Montes, X. L. Deán-Ben, J. C. LópezVázquez, and J. L. Fernández, "Pulsed TV holography measurement and digital reconstruction of compression acoustic wave fields," Meas. Sci. Technol., vol. 22, no. 2, pp. 025109, 2011.

[20] S. F. Wu, "Methods for reconstructing acoustic quantities based on acoustic pressure measurements," J Acoust Soc Am, vol. 124, no. 5, pp. 2680-97, 2008.

[21] K. Andersen, A. Søvik, P. Lunde, M. Vestrheim, and J. Kocbach, "Reciprocity calibration method for ultrasonic piezoelectric transducers in air. Comparison of finite element modelling and experimental measurements," in Proceedings of the 38th Scandinavian Symposium on Physical Acoustics, 2015, pp. 4.

[22] W. Ke, M. Castaings, and C. Bacon, "3D finite element simulations of an air-coupled ultrasonic NDT system," NDT E Int, vol. 42, no. 6, pp. 524$533,2009$.

[23] G. M. Revel, G. Pandarese, and A. Cavuto, "Quantitative validation of an air-coupled ultrasonic probe model by Interferometric laser tomography," in 10th Int Conf on Vibration Measurements by Laser and Noncontact Techniques, Ancona, Italy, 2012, pp. 361-369.

[24] S. J. Sanabria, R. Furrer, J. Neuenschwander, P. Niemz, and P. Schutz, "Analytical modeling, finite-difference simulation and experimental validation of air-coupled ultrasound beam refraction and damping through timber laminates, with application to non-destructive testing," Ultrasonics, vol. 63 , pp. 65-85, 2015.

[25] Y. Wada, D. Koyama, and K. Nakamura, "Acoustic streaming in an ultrasonic air pump with three-dimensional finite-difference time-domain analysis and comparison to the measurement," Ultrasonics, vol. 54, no. 8 , pp. 2119-2125, 2014

[26] A. G. Bashford, D. W. Schindel, D. A. Hutchins, and W. M. D. Wright, "Field characterization of an air-coupled micromachined ultrasonic capacitance transducer," J Acoust Soc Am, vol. 101, no. 1, pp. 315-322, 1997.

[27] J. Song, and D. Chimenti, "Design, fabrication and characterization of a spherically focused capacitive air-coupled ultrasonic transducer," Int. $J$. Appl. Sci. Eng, vol. 4, no. 1, pp. 1-19, 2006.

[28] S. Kramer, S. L. McBride, H. Doug Mair, and D. A. Hutchins, "Characteristics of wideband planar ultrasonic transducers using plane and edge wave contributions," IEEE T Ultrason Ferroel Freq Control, vol. 35, pp. 235-263, 1988.

[29] G. Benny, and G. Hayward, "Beam profile measurements and simulations for air-coupled ultrasonic transducers," 1999 IEEE Ultrasonics Symposium, Vols 1 and 2, pp. 1041-1044, 1999.

[30] L. Schmerr, and J.-S. Song, Ultrasonic nondestructive evaluation systems, New York, NY, USA: Springer, 2007.

[31] M. C. Bhardwaj, "Phenomenally high transduction - air/gas transducers for practical non-contact ultrasonic applications.," Review of Progress in Quantitative Nondestructive Evaluation, D. Thompson and D. Chimenti, eds., pp. 920-927, Chicago, IL, USA: American Institute of Physics, 2009.

[32] D. Algernon, B. Grafe, F. Mielentz, B. Kohler, and F. Schubert, "Imaging of the elastic wave propagation in concrete using scanning techniques: application for impact-echo and ultrasonic echo methods," $J$ Nondestruct Eval, vol. 27, pp. 83-97, 2008. 
[33] V. Bovtun, J. Döring, J. Bartusch, U. Beck, A. Erhard, and Y. Yakymenko, "Ferroelectret non-contact ultrasonic transducers," Appl Phys A, vol. 88, pp. 737-743, 2007.

[34] Y. M. Fang, L. J. Lin, H. L. Feng, Z. X. Lu, and G. W. Emms, "Review of the use of air-coupled ultrasonic technologies for nondestructive testing of wood and wood products," Comput Electron Agric, vol. 137, pp. 79-87, 2017.

[35] M. Kaczmarek, B. Piwakowski, and R. Drelich, "Noncontact ultrasonic nondestructive techniques: state of the art and their use in civil engineering," J Infrastruct Syst, vol. 23, no. 1, pp. B4016003, 2017.

[36] P. T. Christopher, and K. J. Parker, "New Approaches to the Linear Propagation of Acoustic Fields," J Acoust Soc Am, vol. 90, no. 1, pp. 507521, 1991.

[37] D. L. Liu, and R. C. Waag, "Propagation and backpropagation for ultrasonic wavefront design," IEEE Trans Ultrason Ferroelectr Freq Control, vol. 44, no. 1, pp. 1-13, 1997.

[38] M. B. S. Magalhaes, and R. A. Tenenbaum, "Sound sources reconstruction techniques: A review of their evolution and new trends," Acta Acust united $A c$, vol. 90, no. 2, pp. 199-220, 2004.

[39] J. D. Maynard, E. G. Williams, and Y. Lee, "Nearfield Acoustic Holography .1. Theory of Generalized Holography and the Development of Nah," J Acoust Soc Am, vol. 78, no. 4, pp. 1395-1413, 1985.

[40] G. T. Clement, and K. Hynynen, "Forward planar projection through layered media," IEEE Trans Ultrason Ferroelectr Freq Control, vol. 50, no. 12 , pp. 1689-1698, 2003.

[41] G. T. Clement, R. Liu, S. V. Letcher, and P. R. Stepanishen, "Forward projection of transient signals obtained from a fiberoptic pressure sensor," J Acoust Soc Am, vol. 104, no. 3, pp. 1266-1273, 1998.

[42] Y. Du, H. Jensen, and J. A. Jensen, "Investigation of an angular spectrum approach for pulsed ultrasound fields," Ultrasonics, vol. 53, no. 6, pp. 1185-91, 2013.

[43] X. Wu, A. Worthington, M. Gertner, J. Hunt, and M. Sherar, "Characterization of changes in therapeutic ultrasound transducer performance over time using the angular spectrum method," IEEE Trans Ultrason Ferroelectr Freq Control, vol. 54, no. 5, pp. 1028-1035, 2007.

[44] O. Cramer, "The Variation of the Specific-Heat Ratio and the Speed of Sound in Air with Temperature, Pressure, Humidity, and Co2 Concentration," J Acoust Soc Am, vol. 93, no. 5, pp. 2510-2516, 1993.

[45] S. J. Sanabria, U. Hilbers, J. Neuenschwander, P. Niemz, U. Sennhauser, H. Thoemen, and J. L. Wenker, "Modeling and prediction of density distribution and microstructure in particleboards from acoustic properties by correlation of non-contact high-resolution pulsed air-coupled ultrasound and X-ray images.," Ultrasonics, vol. 53, no. 1, pp. 157-170, 2012.

[46] R. Mehra, N. Raghuvanshi, L. Savioja, M. C. Lin, and D. Manocha, "An efficient GPU-based time domain solver for the acoustic wave equation," Applied Acoustics, vol. 73, no. 2, pp. 83-94, 2012.

[47] T. E. Gomez, "Acoustic impedance matching of piezoelectric transducers to the air," IEEE Trans Ultrason Ferroel Freq Control, vol. 51, no. 5, pp. 624-633, 2004.

[48] L. Ambrozinski, S. Song, S. Joon Yoon, I. Pelivanov, D. Li, L. Gao, T. T. Shen, R. K. Wang, and M. O'Donnell, "Acoustic micro-tapping for noncontact 4D imaging of tissue elasticity," Scientific Reports, vol. DOI:10.1038/srep38967, 2016.

[49] T. Conner-Kerr, and M. E. Oesterle, "Current perspectives on therapeutic ultrasound in the management of chronic wounds: a review of evidence," Chronic Wound Care Management and Research, vol. 4, pp. 89-98, 2017.

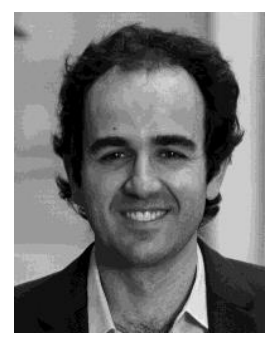

Sergio J Sanabria was born in Vitoria, Spain, in 1984. He received the M. Sc. in Telecommunications Engineering from the University of the Basque Country, Bilbao, Spain in 2007, and his $\mathrm{PhD}$ degree from ETH Zurich, Switzerland in 2012. His dissertation focused on the development of an ACU system for NDE of glued timber structures. From 2012 to 2014, he gained post-doctoral experience in neutron and X-ray synchrotron image processing algorithms. In 2014, he joined the Computer Vision Laboratory at ETH Zurich as a Senior Assistant, where he co-leads the elastrography research and develops a novel ultrasound breast cancer diagnosis device.

Dr. Sanabria is co-author of 16 peer-reviewed papers and holds three patents. He received the Best Young Academics Dissertation Award by the German Society of Non-Destructive Testing (DGZfP) and the Gold Medal Award by the International Academy of Wood Science (IAWS). He has also received best paper awards at the conferences IEEE IUS 2010 and IPCAI 2015. In 2016, he received the Spark Award for the most promising invention registered for a patent at ETH Zurich.

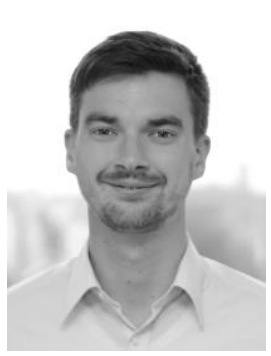

Torben Marhenke was born in Alfeld, Germany, in 1988. He received the M.Sc. degree in mechanical engineering from the Leibniz University Hannover, Germany, in 2014. From 2014 to 2015, he worked in the research and development department at Fagus-GreCon Greten $\mathrm{GmbH} \& \mathrm{Co}$. KG. Since June 2015 he is a $\mathrm{PhD}$ student in the piezoelectric and ultrasonic group at the Institute for Dynamics and Vibration Research of the Leibniz University Hannover in cooperation with Fagus-GreCon. His focus is on NDE of wood-based materials with ultrasound. In 2017 he did a research exchange at ETH Zurich.

He was recipient of the Dr. Jürgen und Irmgard Ulderup Award in 2013 and 2014 for the best Bachelor and Master degrees in mechanical engineering at the Leibniz University Hannover.

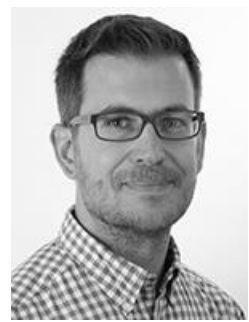

Roman Furrer was born in Wetzikon, Switzerland in 1982. He learned draftsmen at Sulzer Textil in Rueti from 1998 to 2002 and received the diploma $\mathrm{FH}$ in mechanical engineering (2007) at the Universities of Applied Sciences in Rapperswil (HSR).

After studies he worked as an assistant at IPEK, an institute of HSR and joined 2009 the Swiss Federal Laboratories for Materials Science and Technology (Empa). His current field of activity is materials research with non-destructive diagnostic methods, especially ultrasonics, thermograpics and radiographics.

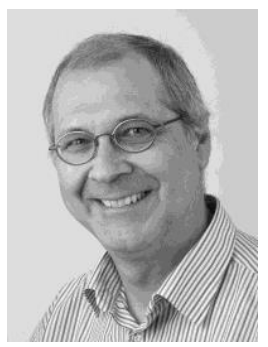

Jürg Neuenschwander was born in Chur, Switzerland, in 1958. He received his MSc degree in physics (1983) and $\mathrm{PhD}$ in natural sciences (1988) at the Swiss Federal Institute of Technology (ETH) in Zurich. 1988-1990 he was post-doc at the High Magnetic Field Laboratory in Grenoble and 1990-1992 he had a position as research scientist at the University of Bern. 1992 he joined the Swiss Federal Laboratories for Materials Science and Technology (Empa) and is presently Senior Scientist at the Transport at Nanoscale Interfaces Laboratory. His current field of activity is materials research with non-destructive diagnostic methods, especially ultrasonics. 